\title{
Teaching Practice of "Ideological and Political Courses"-Taking Definite Integral as an Example Using Three-Implicit and Three-Fusional
}

\author{
Zhonghui Xue, Yuemin Teng, Qianfeng Ma \\ Shanghai Publishing and Printing College, Shanghai, China \\ Email: hnlgxzh@163.com
}

How to cite this paper: Xue, Z.H., Teng, Y.M. and Ma, Q.F. (2020) Teaching Practice of "Ideological and Political Courses"Taking Definite Integral as an Example Using Three-Implicit and Three-Fusional. Open Access Library Journal, 7: e6859. https://doi.org/10.4236/oalib.1106859

Received: September 24, 2020

Accepted: November 6, 2020

Published: November 9, 2020

Copyright $\odot 2020$ by author(s) and Open Access Library Inc.

This work is licensed under the Creative Commons Attribution International License (CC BY 4.0).

http://creativecommons.org/licenses/by/4.0/

\section{(c) (i) Open Access}

\begin{abstract}
In recent years, the Party Central Committee has paid more attention to the ideological education of students. College teachers are constantly exploring how to implement ideological and political education in the classroom teaching process. The author designs and practices the teaching of "Course Ideological and political education" in higher mathematics. Taking the concept of definite integral as an example, this paper introduces how to combine the definite integral with the ideological and political education of college students through the paradigm of "Three-implicit and Three-fusional", so as to play the role of teachers of basic courses in Ideological and political education.
\end{abstract}

\section{Subject Areas}

Education

\section{Keywords}

Advanced Mathematics, Definite Integral, Ideological and Political Courses, Three-Implicit and Three-Fusional

\section{1. 绪论}

2017 年习近平总书记在全国高校思想政治工作会议上指出 “要坚持把立 德树人作为中心环节, 把思想政治工作贯穿教育教学全过程, 实现全程育人、 全方位育人”, “要用好课堂教学这个主渠道, 思想政治理论课要坚持在改 进中加强, 提升思想政治教育亲和力和针对性, 满足学生成长发展需求和期 
待, 其他各门课都要守好一段渠、种好责任田, 使各类课程与思想政治理论 课同向同行，形成协同效应” [1]。这是对 “课程思政” 的科学概括和集中阐 发。教师在课程教学过程中将 “课程思政” 这一主题自然地融入到实际教学 中, 将其贯穿于课程教学目标、教学内容、教学环节、教师的精神风貌等诸 多课堂因素中, “课程思政” 的目标通过这些课堂因素得以体现和落实。在 具体的课程思政范式和方法上出现了一些具有借鉴意义的尝试，如上海出版 印刷高等专科学校滕跃民教授的课程思政教学团队提出的 “三寓三式” 和 “五 化五式” 等 [2] [3]。本文以高等数学常规知识点 “定积分” 为例, 探究了该知 识点的 “三寓三式” 课程思政案例。

\section{2. “课程思政” 教学实践一以定积分为例}

\section{1. 定积分知识点和数学思想}

为便于理解, 我们首先给出定积分的定义。给定函数 $f(x), x \in[a, b]$, 假定 $f(x) \geq 0$, 即函数 $f(x)$ 非负。我们要解决的问题是由函数的曲线 $f(x)$, $x$ 轴、以及 $x=a$ 和 $x=b$ 围成的封闭区域的面积。如图 1 所示。

求曲边梯形的面积的步骤:

1) 分割: 任意插入 $n-1$ 个点, 把区间 $[a, b]$, 分成那个小区间, 形如图 2 所示。 $a=x_{0}<x_{1}<x_{2}<\cdots<x_{n-1}<x_{n}=b, \Delta x_{i}=x_{i}-x_{i-1}$

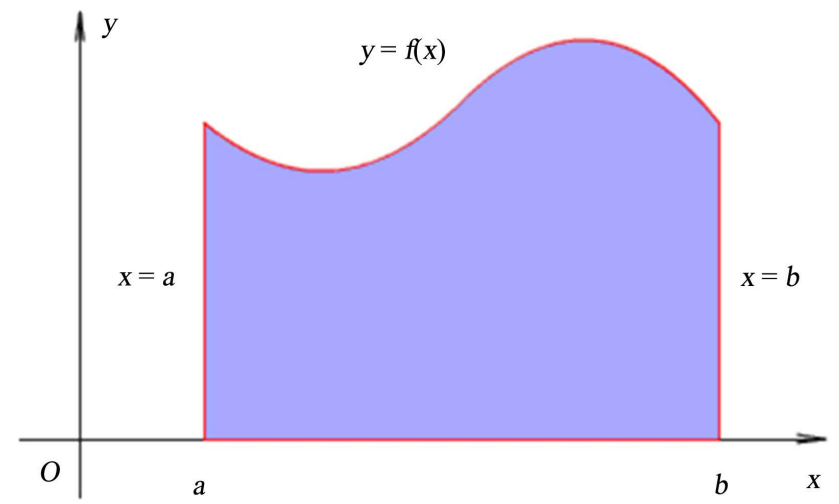

图 1. 所求图形面积的示意图

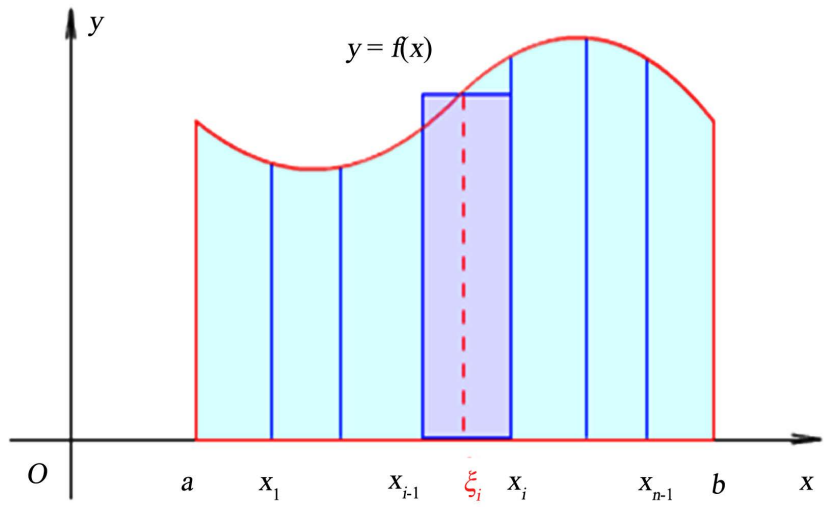

图 2. 所求图形面积分割的示意图 
2) 近似代替: 在区间 $\left[x_{i-1}, x_{i}\right]$ 内, 任意去一点 $\xi_{i}$, 对应的函数值为 $f\left(\xi_{i}\right)$, 则小曲边梯形的面积近似为 $f\left(\xi_{i}\right) \Delta x_{i}$;

3) 求和: 曲边梯形的面积近似为 $\sum_{i=1}^{n} f\left(\xi_{i}\right) \Delta x_{i}$;

4) 取极限: 设 $\lambda=\max \left\{\Delta x_{1}, \Delta x_{2}, \cdots, \Delta x_{n}\right\}$, 则曲边梯形的面积为 $\lim _{\lambda \rightarrow 0} \sum_{i=1}^{n} f\left(\xi_{i}\right) \Delta x_{i}$, 写成通用的定积分表达式记为:

$$
\int_{a}^{b} f(x) \mathrm{d} x=\lim _{\lambda \rightarrow 0} \sum_{i=1}^{n} f\left(\xi_{i}\right) \Delta x_{i}
$$

其中 $a$ 叫做积分下限, $b$ 叫做积分上限, 区间 $[a, b]$ 叫做积分区间, 函数 $f(x)$ 叫做被积函数, $x$ 叫做积分变量, $f(x) \mathrm{d} x$ 叫做被积表达式, $\int$ 叫做积分号。之 所以称其为定积分, 是因为它积分后得出的值是确定的, 是一个常数, 而不 是一个函数。

综合来看, 定积分的定义可以分为四个步骤:

第一步：分割, 即把曲边梯形分割为有限个相邻的小曲边梯形;

第二步: 近似代替, 即任意选择一个分割后的小曲边梯形, 进而任意的 选取分割区间中的一点的对应的函数值作矩形的高, 该分割区间作为矩阵的 底, 进而用该小矩形的面积近似代替小曲边梯形的面积;

第三步: 求和, 即把第一步分割成的有限个小曲边梯形的面积分别用对 应的小矩形的面积替代, 进而求和;

第四步: 求极限, 即把第三步求和的结果取极限。选取其中最大的分割 区间作为取极限的标准, 当最大的分割区间极限为零时, 所有小于该区间的 分割区间的极限一定为零, 进而求在最大分割区间极限为零时, 第三步说的 面积和的极限即为曲边梯形的面积。

从上面的论述我们可以看出, 定积分的概念的形成过程蕴含了一种非常 重要的数学思想: 化整为零和积零为整。定积分思想可以说是一种做事思维, 引导我们认识未知、理解未知、把握未知、控制未知和操作未知的一种思想、 一种理念、一种方法。

\section{2. 寓教于乐 - 元素化合说文解字谈积分}

据许慎说文解字, “积”, 聚也。积, 累也......堆叠也。一-《增韵・昔 韵》; 积土成山, 风雨兴焉......积善成德, 圣心备焉。-—《苗子・劝学》。 单词 calculus 直接来自拉丁语, 后面的-ulus 是个指小名词后缀, 其中的 $\mathrm{ul}$ 表示某种小东西, 后面的-us 是拉丁语中的名词后缀, 在英语中常常脱落或 变成字母 $\mathrm{e}$ 。单词 calculus 保留了拉丁语的拼写方式, 字面意思就是“小石子”。 它是在英语中是个专业术语, 在医学领域表示 “结石”, 在数学领域表示 “微 积分”。因为古人常用小石子来计数, 每块小石子代表着要加的一个微小数 量, 所以数学家就用 calculus 来表示 “微积分”。英文的积分单词为 “integral” 的词根为 “inter-, integr-” 是 “整, 全” 的意思, 而 “integral” 翻译成中文 为 “积分; 部分; 完整; 整体”, 可见在东西方文明中积分或 “integral” 都 包含重要的思想价值和文化价值: 积少成多, 积微成著。 


\section{3. 寓道于教 - 画龙点睛融入定积分中的数学思想}

通过对量变与质变哲学关系的思考, 确定了定积分思想中量变与质变的 关系; 并通过利用定积分思想求解曲边梯形面积的过程, 体现定积分思想中 量变与质变的基本形式、相互关系及其转化过程; 最后, 通过求曲线弧长、 电荷做功等实例, 将定积分思想在数学、现代科学领域所处的地位及其重要 意义做了简要介绍。通过知识的讲解和升华, 提炼出定积分的数学思想:

1) 数学形结合的思想。数是形的数, 形是数的形。定积分概念的引入和 讲解如果采用数形结合的方法会起到事半功倍的效果。可以化抽象为形象; 化冰冷为激情, 变枯燥为有趣。

2) 化整为零的思想: 只要大家静下心来思考, 会发现生活和工作中的很 多事情都是如此, 可以像求曲边梯形面积一样, 先将大事难事细化, 分解成 小事, 从小事入手, 一步一步完成。

3) 积零为整的思想: 当每件小事解决好以后, 就可以组合了。

4) 近似替代的思想: 积零为整后面临的选择就是如何建立确定的面积和 积零为整的面积之间的关系, 这时候就要用到了数学中, 甚至可以说是我们 处理问题时常用的思想方法, 近似替代。近似不是目的, 是手段或者方法, 通过近似的替代找到和真值之间的距离, 需要努力的方向就会自动的显现出 来。

5) 无限逼近的思想: 在上面的近似替代的基础上, 真值和近似值之间的 差距产生的原因是什么也就非常容易的显现出来, 那么数学中的极限思想方 法就会自然而生。此处可以告知学生, 将生活和工作中所遇到的事情、问题 和困难, 采用无限逼近的极限思想, 那么事情将会完成的越完美, 离事情的 成功、问题的解决和困难的客服就非常非常近了。很多时候, 细节决定成败。

6) 归纳和演绎的思想: 由部分到整体、个别到一般的推理是归纳推理, 由一般到特殊的推理是演绎推理。不规则图形的面积的求解、变力做功问题、 变速直线运动的路程的计算等问题都是一般问题, 但是一般问题中蕴含着共 性, 定积分就是从一般的问题中抽取了共性, 忽落一般性, 通过逻辑推理和 程序化的方法建立起来的一个通用的概念。概念形成之后进而推广到具体的 问题, 如不规则图形的面积、变力做功、变速运动的路程等具体问题的求解 就会变得简单易行。

因此我们认为教师改变教学方式, 学生自然会有所成长。学校育人的成 果, 不是一两年就能立笔见影。作为一种思维工具、认识方法, 学校像栽培 器, 我们等待学生在社会上 “开花结果”, 为 “两个一百年” 去奋斗。要知 道立德树人是一个润物细无声的过程。

\section{4. 育德于教 - 专题嵌入定积分中的德育因子}

以定积分的知识点和思想为基础, 我们深入探究这一人类文明重要成果 所蕴含的丰富的思政元素, 归纳如下:

1) 有恒心, 一切皆有可能。

“银而舍之, 朽木不折; 银而不舍, 金石可镂。”这句话出自于《荀子・劝 学》, 其字面意思是用刀刻东西, 如果中途停止, 虽然是腐朽的木头也不能 
刻断; 如果不停地刻下去, 即便是金石也能雕刻成功。引申义是说人们无论 是做什么事情, 一定要贵在坚持, 不能知难而退, 面对困难奋勇前进, 胜利 终将属于自己。

2) 量的积累引起质变。

质量互变规律是唯物辩证法的基本规律之一。量变会促使事物的发展, 但是这需要量的积累, 积累的多了, 就会引起事物的发展变化。不断进步, 积沙成丘, 做任何事, 都不像我们想象的那么简单, 我们会遇到这样那样的 困难, 但是困难并不可怕, 可怕的是我们无法下定决心去克服它。困难是最 好的挑战。只有在有挑战的时候, 我们才能不断进步, 不断进步之后, 成功 只是时间问题。所以你不必等待有人告诉你, 你成功了。只要你每天不断进 步和突破, 你每天都是一个成功的人。如果你每天都能取得进步, 你计算过 三年后会有多少进步吗? 有时人生就是这样, 只要你每天都有一点进步, 坚 持不解, 总有一天你会惊讶地发现, 在不知不觉中, 你已经在同龄人中脱颖 而出, 有能力承担更多的责任; 在不知不觉中, 你的业绩已经在同事中脱颖 而出, 你的业绩在公司考核中也已遥遥领先。相信 “积沙成丘” 的真理, 不 投机不取巧, 踏踏实实做事, 每天都有一点进步, 你就一定能够成功。集腋 成表, 汉语成语, 拼音是 jí yè chéng qiú, 意思是狐狸腋下的皮虽很小, 但聚 集起来就能制一件皮袍。比喻积少成多。出自《慎子 - 知忠》。《慎子 - 知 忠》: “狐白之震, 盖非一狐之皮也。”【近义词】：积土成山、积少成多、 聚沙成塔【反义词】：杯水车薪、一口吃一个胖子。

然而, 每个人对成功有不同的定义。在我看来成功最简单的定义是每天 都有一点进步。故不积跬步, 无以至千里; 不积小流, 无以成江海。骐瀷一 跃, 不能十步; 驽马十驾, 功在不舍。银而舍之, 朽木不折; 银而不舍, 金 石可镂。

3) 勿以善小而不为, 勿以恶小而为之。勿以善小而不为, 勿以恶小而为 之系蜀汉先主刘备所言, 出自《三国志 - 蜀书 - 先主传》, 意思是不要因为 是件较小的坏事就去干, 不要因为是件较小的善事就毫不关心。这一哲学道 理告诉我们, 小恶不断, 将成大恶; 小善常为, 将会成为对社会有用的人。

4) 透过现象看本质, 抓住事物的共性也就是本质才能升华和收获。

世界是复杂的也是简单的。复杂在每个事物都有自己的个性的一方面, 而简单又在于它们具有本质上的共性。比如化学元素周期表中的元素 118 种 却可以构建出如此纷繁复杂, 多彩多姿的世界万物。并搬动了数以千万倍于 己的巨蟒, 这是无数只蚂蚁结成共同目标, 协调一致, 并为之奋斗的团队精 神才能完成。团队精神是大局意识、协作精神和服务精神的集中体现, 是以 协同合作为核心, 反映了个体利益和集体利益的统一, 保证集体高效运转的 一种精神。

5）遵循原则做事，灵活处理困难。

在应用分部积分法求解定积分时我们需要按照一定的原则进行凑微分, 再利用分部积分实现由难到易的转化, 这一方法可以让我们在教学中引导学 生在实际生活中凡事都需要遵循一定的原则, 如果最开始的决策是错误的, 那事情很可能发展得越来越复杂, 越发不可收拾, 在能预见这一后果时就应 
该及时改变思路, 进而化繁为简, 大事化小。

\section{3. 小结}

本文以《高等数学》课程中的定积分概念为例, 介绍如何将定积分知识 点与大学生的思想政治教育想结合，与人生哲理和做事方法相结合。在立足 课程本身特色的基础上，提炼出爱国情怀、社会责任、法制意识、人文精神、 文化自信等要素，从而实现思政寓课程、课程融思政，充分发挥专业教师在 思想政治教育中的作用。

总而言之, 在课堂教学当中贯穿课程思政, 是一项长期而艰巨的任务, 在《高等数学》课程教学当中, 具有丰富的思想价值值得的深入的挖掘, 需 要不断地进行探索, 从而更好地将课程思政落实到课堂教学。

\section{致 谢}

本文受 2018 年度教育部高校示范马克思主义学院和优秀教学科研团队 建设项目 (18JDSZK012)、上海出版印刷高等专科学校 “课中课” 国家级教学 成果奖应用推广工程子项目 (ZK-2020-032)，2020 年上海出版印刷高等专科学 校思政重点课题和 2020 年上海出版印刷高等专科学校高教研究课题 (GJYJ-2020-10)资助。

\section{Conflicts of Interest}

The authors declare no conflicts of interest regarding the publication of this paper.

\section{References}

[1] 赵婀娜, 丁雅诵. 全国高校思想政治工作会议以来学校思想政治理论课建设综述 [N]. 人民日报(第 1 版), 2019-3-18.

[2] 滕跃民, 张玉华, 肖纲领. 高职专业“课程思政”的“道法术器”改革 [J]. 辽宁高职 学报, 2018(8): 53-55.

[3] 滕跃民, 张玉华, 马前锋, 汪军, 孟仁振. 同向同行: 知识传授与价值引领同频共 振一一上海出版印刷高等专科学校“课中课”课程思政改革探析 $[\mathrm{N}]$. 中国教育报 (第 11 版), 2019-6-19. 


\section{Appendix (Abstract and Keywords in Chinese)}

\section{定积分课程思政三寓三式的教学实践}

摘要: 近年来, 党中央加强对学生思想教育工作的重视, 高校教师在不断 探索如何将思政教育落实在课堂教学过程当中。作者针对高等数学课程进行了

“课程思政” 教学的设计和实践, 本文以定积分概念为例, 介绍如何将定积分 通过三寓三式的范式与大学生的思政政治教育相结合, 从而发挥基础课教师在 思想政治教育中的作用。

关键词: 高等数学, 定积分, 课程思政, 三寓三式 